\title{
Os movimentos contestatórios no Serviço Social iberoeuropeu e da América do Norte no período de 1960 a 1980
}

Social contestation movements in Ibero-European and North American Social Work from 1960 to 1980

\author{
Alexandra A. L. T. S. Eiras* \\ Maria Carmelita Yazbek** \\ Cláudia Mônica dos Santos***
}

\begin{abstract}
Resumo - Este artigo constitui-se como parte da pesquisa O Movimento de Reconceituação do Serviço Social na América Latina (Argentina, Brasil, Chile e Colômbia): determinantes históricos, interlocuções internacionais e memória. Nossa ênfase circunscreve-se a Portugal, Espanha, EUA e Canadá (1960-1980). Desse modo, pretendemos identificar as referências teórico-metodológicas do Serviço Social nesse período, em seus nexos com os "movimentos contestatórios" e com o "movimento de reconceituação latino-americano" (MRLA). Indagamos acerca da relação entre o MRLA e o Serviço Social crítico e/ou radical, considerando suas particularidades, antecedentes, expressões e desdobramentos. Apresentamos, assim, um panorama econômico, político, social e cultural da conjuntura desses países à época. Apresentamos, ainda, os movimentos do Serviço Social crítico e/ou radical e suas referências ético-políticas e teórico-metodológicas, as quais os distinguem do Serviço Social tradicional. Por fim, indicamos, quando pertinente, as interlocuções desses movimentos/produções com o MRLA.

Palavras-chave: Serviço Social; Movimento de Reconceituação latinoamericano; movimentos contestatórios na Europa ibera e na Ámérica do Norte.
\end{abstract}

Abstract - This article is part of the research "The Movement of Reconceptualization of Social Work in Latin America (Argentina, Brazil, Chile and Colombia): historical determinants, international interlocutions and me-

\footnotetext{
* Doutorado em Serviço Social (ESS/UFRJ). Vice-diretora da Faculdade de Serviço Social da Universidade Federal de Juiz de Fora (UFJF). Docente e pesquisadora do Programa de Pós-Graduação em Serviço Social (UFJF). Correspondência: Universidade Federal de Juiz de Fora: Rua José Lourenço Kelmer, s/n - Campus Universitário Bairro São Pedro, Juiz de Fora - MG. CEP: 36036-900. Email: <alexandra.eiras@ufjf.edu.br>.

** Doutorado em Serviço Social (Pontifícia Universidade Católica de São Paulo). Pós-doutorado (IEA USP). Docente e pesquisadora do Programa de Pós Graduação em Serviço Social. Professora visitante de universidades de África, Portugal e Argentina. Pesquisadora 1 A do CNPq. Correspondência: Rua Dr. Barachisio Lisboa, 140, São Paulo-SP.CEP: 05441-090.Email:<mcyaz@uol.com.br>.

*** Doutorado em Serviço Social (ESS/UFRJ). Pós-doutorado (ISMT/Coimbra/Portugal). Professora aposentada, colaboradora e pesquisadora no Programa de Pós-Graduação em Serviço Social (UFJF). Professora convidada na Universidade Lusófona do Porto. Correspondência: Rua Miguel José Mansur, 400/apt. 1102, Bairro Cascatinha, Juiz de Fora - MG. CEP: 36033-250. Email: <cmonicasantos@gmail.com>.
} 
mory." Our emphasis is limited to Portugal, Spain, USA and Canada (19601980). In this research we intend to identify the theoretical-methodological references of social work in this period, in its links with the social contestation movements and with the Latin American reconceptualization movement (MRLA). We inquire about the relationship between the MRLA and the critical and radical social work, considering its particularities, antecedents, expressions and aftereffects. In this article, we present an economic, political, social and cultural panorama of the conjuncture of these countries at the time. We also present the movements of critical and radical social work and both their ethical-political and theoreticalmethodological references, which distinguish them from traditional social work and indicate, when pertinent, the interlocutions of these movements and productions with the MRLA.

Keywords: social work; Latin American reconceptualization movement; social contestation in Iberian Europe and North America.

\section{Introdução}

Neste artigo - em âmbito preliminar -, apresentamos parte da bibliografia identificada em nossa pesquisa ${ }^{1}$ acerca do Serviço Social na Europa ibera (Portugal e Espanha) e na América do Norte (EUA e Canadá), no período de 1960 a 1980, tendo como referência e possível interlocução o Movimento de Reconceituação do Serviço Social na América Latina (MRLA), cuja datação histórica consensual na bibliografia sobre o tema remete ao período de 1965 a 1975 (NETTO, 1991; ALAYÓN, 2005; FALEIROS, 2005). Tal movimento, em nossa compreensão, expressou o novo posicionamento ético e político do Serviço Social, alinhado às lutas progressistas e aos novos referenciais teórico-metodológicos que buscaram superar as referências utilizadas pelo Serviço Social tradicional.

Serviço Social tradicional: a prática empirista, reiterativa, paliativa e burocratizada dos profissionais, parametrada por uma ética liberal-burguesa e cuja teleologia consiste na correção - desde um ponto de vista claramente funcionalista - de resultados psicossociais considerados negativos ou indesejáveis, sobre o substrato de uma concepção (aberta ou velada) idealista e/ ou mecanicista da dinâmica social, sempre pressuposta a ordenação capitalista da vida como um dado fatual ineliminável. (NETTO, 1991, p. 118).

O debate sobre o MRLA é polêmico; há divergências que manifestam, inclusive, a particularidade desse processo em cada país onde destaca-

\footnotetext{
1 Pesquisa intitulada Movimentos contestatórios na Europa e América do Norte no período de 1960/1980 e Movimento de Reconceituação no Serviço Social na América Latina: aproximações possíveis, coordenada por Marilda V. Iamamoto (Uerj) e aprovada no edital de 2016 do CNPq Movimento de Reconceituação do Serviço Social na América Latina (Argentina, Brasil, Chile e Colômbia), envolvendo pesquisadores de diversos países.
} 
damente o movimento se expressou: Argentina, Uruguai, Chile e Brasil. Mas, na bibliografia sobre o tema, há uma convergência: o MRLA é compreendido como um movimento heterogêneo, no qual emerge um posicionamento ético-político que se compromete com a realidade social da America Latina e explicita o lugar do Serviço Social na reprodução das desigualdades sociais, bem como sua função social, implicação sociopolítica e valores ideológicos, com pretensão de intervir na alteração dessa realidade. Desse modo, os trabalhadores sociais (assistentes sociais) questionam a neutralidade técnica, recusam a importação de referências norte-americanas e combatem a "técnica transplantada". Simultaneamente, buscam construir referências latino-americanas para a ação profissional. Há também uma construção que transcende os países, que se expressa na criação de organizações de trabalhadores sociais de caráter latino-americano, como a Asociación Latinoamericana de Enseñanza en Trabajo Social (Alaets) e o Centro Latinoamericano de Trabajo Social (Celats), que impactam sobre a organização dos assistentes sociais no continente, bem como na elaboração e divulgação das novas referências produzidas pelo MRLA.

Há relação entre o MRLA e os processos de lutas e enfrentamentos sociais na particularidade de cada país, os quais interpelam o Serviço Social, assim como articulações progressistas que resistem aos processos repressivos, implementados através de ditaduras civis-militares em diferentes períodos Brasil, 1964; Uruguai, 1972; Chile, 1973; Argentina, 1976. Essas ditaduras foram heterogêneas, bem como suas resistências (MOLJO, 2005). A vinculação do Serviço Social com esse processo diretamente ou com suas demandas constitui os fundamentos sócio-históricos de alteração das bases para o novo posicionamento ético-político.

Ao questionar seus referenciais, a profissão assume as inquietações e insatisfações de uma conjuntura histórica de intenso movimento políticocultural, que reúne profissionais, intelectuais, trabalhadores e segmentos médios e das classes populares em torno da luta anti-imperialista na defesa de projetos de transformação social. Nesse contexto destacam-se as transformações da Igreja Católica, agora sob a égide do Concílio Vaticano II (1962), dando origem à chamada Teologia da Libertação, que irá interferir nas lutas contestatórias que marcaram o continente neste período histórico.

É no bojo deste movimento e em seus desdobramentos históricos que se definem e se confrontam diferentes tendências na profissão, as quais incidem nos seus fundamentos teóricos e metodológicos e na direção social de sua intervenção. Marcam esse processo as experiências de grupos de assistentes sociais, vinculados à esquerda católica e a outros grupos políticos de esquerda, aos projetos de educação de base e de organização popular em comunidades urbanas e rurais, inspirados pela educação para a libertação e pelo método de alfabetização de Paulo Freire.

Por outro lado, o Serviço Social tradicional latino-americano recebeu influência direta e sustentava-se nas produções europeias (franco- 


\section{heVistg all pavtg}

\} OS MOVIMENTOS CONTESTATÓRIOS NO SERVIÇO SOCIAL - EIRAS, A. A. L. T. S.; YAZBEK, M. C.; SANTOS, C. M. \} DOI: $10.12957 /$ REP.2017.32744

belgas) ${ }^{2}$ e norte-americanas. A tradição franco-belga resultou de influências da Escola de Serviço Social de Bruxelas, que oferecia um curso de Serviço Social voltado para a ação social. Esta, por sua vez, recebeu influência do cardeal Mercier e das Ligas Operárias Femininas, cuja perspectiva era a ação social. Na França, a formação em Serviço Social era oferecida pela Escola Normal Social de Paris (primeira escola de Serviço Social da França, criada em 1911) e na Escola Superior de Estudos Sociais do Instituto Católico de Paris.

É necessário assinalar que esta matriz se encontra na gênese da profissão em quase toda a América Latina, embora com particularidades diversas e coexistindo com outras tendências, como, por exemplo, na Argentina e no Chile, onde vai somar-se ao racionalismo higienista ${ }^{3}$.

A influência norte-americana inicia-se em 1941, quando foram concedidas bolsas de estudos a professores de escolas da América, que vão se aprimorar nas abordagens profissionais desenvolvidas no âmbito da matriz positivista, na perspectiva de ampliar os referenciais técnicos para a profissão. Este processo reitera, para a profissão, o caminho do pensamento conservador pela mediação das Ciências Sociais.

No decorrer do MRLA, houve uma recusa e uma busca de superação das referências teóricas tradicionais. Foi um momento ímpar em termos de unidade e diversidade acerca dos questionamentos das bases conservadoras do Serviço Social, que suscitou diferentes debates e elaborações teóricas nos distintos países latino-americanos.

A elaboração de novas referências no Serviço Social latino-americano, sustentadas na perspectiva crítica, com aproximações à tradição marxista, expôs uma nova perspectiva para apreensão e análise da profissão e de suas demandas sócio-históricas. Nesse período, observamos um protagonismo do Serviço Social latino-americano na construção de novos posicionamentos e novas referências, distanciando-se e questionando as referências teóricas europeias e norte-americanas (EIRAS; SANTOS, 2017).

Contudo, sabemos que tanto na América do Norte como na Europa (Inglaterra, Reino Unido, Espanha, Portugal, Alemanha, dentre outros) houve movimentos contestatórios reformistas ou revolucionários que influenciaram o Serviço Social nesses países, abrindo novos horizontes e novas vinculações ético-políticas. Além disso, a bibliografia indica a emergência ou ativação do Serviço Social crítico e/ou radical nesse período nesses países.

Desse modo, indagamos sobre o contexto em que essas referências emergem, quais são suas origens e vinculações, a relação entre essas expressões e os movimentos contestatórios do período, em quais canais essa perspectiva se expressa (formação, produção acadêmica, exercício profis-

\footnotetext{
${ }^{2}$ O Serviço Social em Portugal e Espanha também tiveram em suas origens a influência franco-belga.

3 Ideário do movimento de médicos que exigiam a intervenção ativa do Estado sobre a questão social pela criação da assistência pública, que deveria assumir um amplo programa preventivo na área sanitária, social e moral.
} 


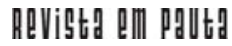

\} OS MOVIMENTOS CONTESTATÓRIOS NO SERVIÇO SOCIAL - EIRAS, A. A. L. T. S.; YAZBEK, M. C.; SANTOS, C. M. \} DOI: $10.12957 /$ REP.2017.32744

sional), o que estão considerando por Serviço Social crítico e/ou radical, bem como a natureza e conteúdo dessa crítica.

No esforço preliminar de responder às perguntas que deram origem a este estudo, este artigo estrutura-se em dois tópicos. No primeiro, apresentamos um panorama das questões histórico-econômicas e dos movimentos contestatórios político-sociais relevantes no período analisado (1960 a 1980). No segundo, indicamos os movimentos do Serviço Social crítico ou radical - suas referências ético-políticas e teórico-metodológicas, as quais o diferenciam do Serviço Social tradicional naqueles países (EUA, Canadá, Portugal e Espanha). Apontamos, quando pertinente, as interlocuções desses movimentos/produções com o MRLA.

\section{Panorama histórico-econômico e movimentos contestatórios (1960 a 1980)}

Como sabemos, os anos de 1960 foram decisivos para grandes transformações no mundo em todos os domínios. A particular conjuntura dessa década assinala redefinições da ordem capitalista internacional e uma crise de fundo da "civilização urbano-industrial", que se irradia por todas as esferas da vida social. Uma referência emblemática desse contexto é o "maio de 1968", expressão de uma fenomenal conjugação de fatores e predisposição cultural e política para as mudanças que colocam em xeque a ordem burguesa e o conjunto de suas instituições. Na América Latina, esse processo se cruza com expectativas de mudança desencadeadas a partir da Revolução Cubana.

Uma das questões centrais em nossa abordagem nesta pesquisa remete ao processo de reprodução social da ordem capitalista no período analisado. Naquele momento, o capitalismo se expressa como modo de produção/reprodução consolidado, que possui como antagonista o socialismo real vinculado à URSS. A bipolarização do mundo, acentuada no pós-guerra, é um elemento fundamental, assim como a alteração progressiva desse contexto, que se desenvolve até o final da década de 1980, na derrocada do sistema socialista. Não analisaremos, neste artigo, a relação e as particularidades histórico-econômicas entre capitalismo e socialismo. Contudo, entendemos que o contexto de polarização fortalecia posicionamentos e demandas progressistas, seja pelo relativo sucesso do socialismo soviético, que permitiu sua expansão como potência mundial, seja pela "ameaça" de novos processos revolucionários de cunho socialista. Tais processos "forçavam" a construção de alternativas reformistas, no âmbito do capitalismo, que combinaram com uma base material favorável de desenvolvimento econômico, industrial e tecnológico capaz de prover o acesso das massas ao consumo. 


\section{ReVistg QIII PaVtg}

\} OS MOVIMENTOS CONTESTATÓRIOS NO SERVIÇO SOCIAL - EIRAS, A. A. L. T. S.; YAZBEK, M. C.; SANTOS, C. M. \} DOI: $10.12957 /$ REP.2017.32744

Os países que analisaremos estão inseridos na lógica de reprodução social do capitalismo, em posições econômico-sociais distintas. De um modo geral, Hobsbawm (1996, p. 264) considera que "o capitalismo foi bem-sucedido em sua reestruturação (pós-guerra) que permitiu aos Estados planejar e administrar a modernização econômica e aumentou enormemente a demanda, evidenciando-se o compromisso com a seguridade social e previdenciária", formando "um mercado de consumo de massa para bens de luxo que agora podiam passar a ser aceitos como necessidades". A capacidade produtiva da economia mundial foi multiplicada com uma "divisão internacional do trabalho muito mais elaborada e sofisticada" (HOBSBAWM, 1996, p. 264). "Os países que compunham o núcleo do capitalismo ocidental comerciavam, é claro, com o mundo de além-mar, e com grande vantagem, pois os termos de comércio os favoreciam - ou seja, podiam obter matériasprimas e alimentos mais baratos" (HOBSBAWM, 1996, p. 264). Mesmo assim, "o que de fato explodiu foi o comércio de produtos industrializados, sobretudo entre os países centrais industriais. O comércio mundial de manufaturas multiplicou-se por mais de dez em vinte anos após 1953" (HOBSBAWM, 1996, p. 265). "A reestruturação do capitalismo e o avanço na internacionalização da economia foram fundamentais e explicam as alterações que se processaram [no âmbito sociocultural], as quais não podem ser entendidas apenas como produto da revolução tecnológica" (HOBSBAWM, 1996, p. 265). Entre as alterações, destaca-se a substituição do Estado Liberal pelo Estado Social, noção de conteúdo anglo-saxônico e reativo às políticas levadas a cabo pelos regimes fascistas e pela necessidade de reconstrução das economias europeias no pós-guerra.

Esse Estado Social seria o Estado da sociedade industrial. Nessa direção, do pós-guerra até 1960 houve melhorias nas condições de vida para os trabalhadores e a população nos países centrais do desenvolvimento capitalista. É importante ressaltar que tanto Portugal como a Europa do Sul não chegaram a constituir pleno Estado Providência, sendo considerável o atraso de Portugal em relação à União Europeia na adoção de políticas sociais consequentes face às necessidades sociais da população.

Cabe ainda destacar que o modelo keynesiano, conjunto de contribuições teóricas de J. M. Keynes, no âmbito da economia e da intervenção do Estado, ao propor a necessidade de crescimento econômico e a extensão de um maior bem-estar para a população, foi fundamental para equilibrar a economia europeia do pós-guerra.

De acordo com Hobsbawm (1996, p. 267), isso repercutiu nas propostas dos partidos socialistas e nos movimentos trabalhistas, que "enquadraram-se prontamente no novo capitalismo reformado, porque para fins práticos não tinham política econômica própria, a não ser, os comunistas, cuja política consistia em adquirir poder e depois seguir o modelo da URSS". Nesse período, a esquerda concentrava-se em "melhorar as condições de seus eleitorados operários e em reformas sociais para esse fim [...] um capita- 


\section{hevistg a p paעtg}

\} OS MOVIMENTOS CONTESTATÓRIOS NO SERVIÇO SOCIAL - EIRAS, A. A. L. T. S.; YAZBEK, M. C.; SANTOS, C. M. \} DOI: $10.12957 /$ REP.2017.32744

lismo reformado, que reconhecesse a importância da classe trabalhadora e das aspirações socialdemocratas, Ihes parecia bastante adequado" (HOBSBAWM, 1996, p. 267). O autor conclui que "O clima da década de prosperidade [pós-guerra, anos 1950] era contra a esquerda. Não era tempo de mudança" (HOBSBAWM, 1996, p. 278).

Contudo, na década de 1960, "o centro de gravidade mudou para a esquerda" e "os partidos políticos de esquerda alcançam o auge" (HOBSBAWM, 1996, p. 278). Esse é o período da crise do modelo de produção fordista/keynesiano, base material do Estado de Bem-Estar Social europeu, com "60\% de orçamentos vinculados à seguridade social" (HOBSBAWM, 1996, p. 279). O aumento da demanda por consumo, por parte da classe trabalhadora, "afeta a disputa por salários mais altos e por reajustes constantes" (HOBSBAWM, 1996, p. 279), com expectativa de continuidade do pleno emprego. A inflação contínua é um problema acentuado pela "explosão mundial de salários" no fim da década de 1960 (HOBSBAWM, 1996, p. 279). O "estado de "espírito" é de luta e enfrentamento [rebeliões]" (HOBSBAWM, 1996, p. 279).

Os movimentos expressam expectativas para manter e ampliar o acesso aos bens produzidos, assim como a disposição para resistir aos ataques ao Estado de Bem-Estar Social e para manter a seguridade social alcançada. Os movimentos contestatórios do período em análise (1960 a 1980) vinculam-se, com suas particularidades, a esses processos.

Nesse sentido, a industrialização implicou no aumento do número de trabalhadores, tendência que se reverte a partir de 1980. O desenvolvimento tecnológico e a expansão econômica impactaram na demanda por novos profissionais e por qualificação técnica. Hobsbawm (1996) analisa a "revolução social" ocorrida neste período, que envolveu a "morte do campesinato", a expansão do ensino superior, o protagonismo da juventude e das mulheres. Conforme referimos, destacam-se, na década de 1960, os eventos que ficaram conhecidos como "maio de 1968", protagonizados pelos jovens estudantes em diferentes países.

Segundo Hobsbawm (1996, p. 432), há uma "aproximação da geração estudantil rebelde" aos "inspiradores da revolução radical e total transformação social", "Marx, os ícones não stalinistas da Revolução de Outubro e Mao". O marxismo "atraía grande número de intelectuais (desde o período antifascista)", mas um tipo próprio de marxismo, "voltado para o seminário e para a academia", elaborado na sala de aula e não pela experiência de trabalho. Para ele, "a revolta estudantil de fins da década de 1960 foi a última arremetida da velha revolução mundial". Desse modo, "foi revolucionária tanto no antigo sentido utópico de buscar uma inversão permanente de valores, uma sociedade nova e perfeita, quanto no sentido operacional de procurar realizá-la pela ação nas ruas e barricadas, pela bomba e pela emboscada na montanha" (HOBSBAWM, 1996, p. 434). 


\section{ReVistg QIII PaUtg}

\} OS MOVIMENTOS CONTESTATÓRIOS NO SERVIÇO SOCIAL - EIRAS, A. A. L. T. S.; YAZBEK, M. C.; SANTOS, C. M. \} DOI: $10.12957 /$ REP.2017.32744

Nos EUA, tais movimentos tiveram a participação de grande número de intelectuais, e "muitos foram recrutados para a profissão acadêmica" (HOBSBAWM, 1996, p. 434). Ainda nos EUA, embora na condição de potência hegemônica, há um conjunto de lutas internas que expressam as contradições sociais próprias desta sociedade, como a contestação da participação do país na Guerra do Vietnã e o Movimento pelos Direitos Civis dos Negros, do qual é emblemática a manifestação liderada por Martin Luther King em Washington, com mais de 200 mil pessoas, em 28 de agosto de 1963.

No contexto europeu, a insatisfação da juventude estudantil encontra ressonância junto ao movimento sindical, desencadeando um conjunto de greves e reivindicações dos trabalhadores. A contestação estudantil também envolve demandas democráticas, no âmbito da formação acadêmica na relação entre alunos e professores (EIRAS, 2006). Os movimentos também se expressam no campo da adesão às lutas pela descolonização, empreendida pelos países submetidos aos domínios de França, Portugal, Inglaterra.

Na Espanha e em Portugal predominam ditaduras durante esse período. Nesses países, manifesta-se um conjunto de movimentos que enfrentam o regime ditatorial. Em Portugal, observa-se o protagonismo do operariado e sua organização no Partido Comunista (NETTO, 1986) como um elemento importante no processo da "Revolução dos Cravos" e do fim da Ditadura Salazarista.

Desse modo, o período analisado abarcou um conjunto de movimentos políticos, sociais e culturais diferenciados, com a presença ou não das organizações dos trabalhadores, como sindicatos e partidos, aqui designados como "movimentos contestatórios". Houve convergência para os movimentos de esquerda, como indica Hobsbawm, mas sua caracterização foi diferente em relação aos processos sociais que originaram as posições políticas de esquerda na Europa do século XIX.

Assim, em face dessa diversidade e dado o caráter inicial desta pesquisa, utilizamos a denominação genérica "movimentos contestatórios" e vamos indicá-los, a seguir, considerando a relação do Serviço Social com tais movimentos, em cada país.

\section{Movimentos contestatórios e Serviço Social}

Nossa hipótese é a de que, concomitante ao MRLA, o Serviço Social em Portugal, Espanha, Canadá e EUA construiu proposições críticas ao Serviço Social tradicional, apresentando, inclusive, algum posicionamento ético-político de caráter socialista com horizonte emancipatório. Por que escolhemos esses países?

O Serviço Social latino-americano teve influência do Serviço Social norte-americano. A política econômica norte-americana envolveu a América 


\section{hevistg a p paעtg}

\} OS MOVIMENTOS CONTESTATÓRIOS NO SERVIÇO SOCIAL - EIRAS, A. A. L. T. S.; YAZBEK, M. C.; SANTOS, C. M. \} DOI: $10.12957 /$ REP.2017.32744

Latina, principalmente no período Pós-Segunda Guerra Mundial, pela estratégia desenvolvimentista e, posteriormente, pelo apoio da CIA aos golpes civis-militares realizados em vários países. Como apresentamos na introdução, um dos pontos de convergência do MRLA foi o "anti-imperialismo", presente nas lutas sociais empreendidas neste continente. Desse modo, o Serviço Social norte-americano e os EUA são centrais para a nossa pesquisa.

A relação entre Portugal e Espanha e a América Latina é inerente à formação latino-americana. Mas, no que tange ao Serviço Social, essa relação não se expressou de modo central, embora a influência francobelga tenha sido um elemento comum na origem da profissão. No período analisado (1960-1980), houve uma aproximação entre o MRLA e a Europa ibera. O que destacamos nesse processo foi o fato de Portugal e Espanha estarem sob o regime de ditaduras, assim como outros países da América Latina, ainda que com características diferentes. Há, também, uma interlocução sociocultural, promovida pela proximidade linguística, e um trânsito de apoio e solidariedade entre profissionais perseguidos e exilados face aos regimes autocráticos, que aproximou o Serviço Social nesse período na interlocução entre esses países.

A escolha do Canadá também está vinculada a essa interlocução no período analisado e à emergência de referências críticas significativas, em diálogo com as construções do Serviço Social chileno, na década de 1970. Até o momento, pelos dados que estamos analisando, tal interlocução restringe-se a Quebec.

A seguir, apresentamos um breve estado da arte dos movimentos críticos ao Serviço Social tradicional nesses países e suas vinculações aos processos sociais em desenvolvimento no período.

\subsection{EUA e Canadá}

David Wagner (1991) afirma que nos EUA houve dois grandes períodos de movimentos radicais, repercutindo no chamado "Serviço Social radical" (SSR) 4 . O primeiro ocorreu entre 1930 e $1940^{5}$ e o segundo nos anos de 1960, chegando a 1980. Para ele (WAGNER, 1991, p. 82), o ponto alto desse movimento ocorreu entre 1974-1979, resultado do "severo declínio econômico de 1973", com sérias implicações para os assistentes sociais. Para o autor, o termo "radical" caracteriza os assistentes sociais que se unem em organizações e/ou explicitam seu apoio às causas de esquerda (WAGNER, 1991, p. 97). Ele explica que o SSR não está necessariamente

\footnotetext{
${ }^{4}$ Para Wagner (1991), as referências principais do SSR são: Frances Fox Piven e Richard Cloward, Jeffrey Galper (traduzido no Brasil), Roy Bailey e Mike Brake, autores adeptos do SSR.

${ }^{5}$ Entre 1929 e 1942, um grupo minoritário de assistentes sociais, conhecido como Rank and File, questionou os valores do sistema socioeconômico americano, aliando-se aos movimentos dos trabalhadores. Criticavam o plano governamental "New Deal", considerando que este não ajudava a sociedade, mas sim a indústria e a agricultura.
} 


\section{ReVistg QIII PaVtg}

\} OS MOVIMENTOS CONTESTATÓRIOS NO SERVIÇO SOCIAL - EIRAS, A. A. L. T. S.; YAZBEK, M. C.; SANTOS, C. M. \} DOI: $10.12957 /$ REP.2017.32744

atrelado a uma teoria e indica a existência de várias organizações de assistentes sociais radicais durante os anos 1970 e 1980 quais sejam: Radical Alliance of Social Service Workers (RASSW) e Social Workers Action for Welfare Rights (SWAWR), ambas situadas em Nova York; Union of Radical Human Service Workers (URHSW) e Coalition for Basic Human Needs $(\mathrm{CBHN})$, situadas em Boston. Igualmente, havia grupos de Serviços Sociais radicais, como o grupo nacional Bertha Capen Reynolds Society (BCRS). Importante também, neste período, foi a criação da Revista Catalyst: A Socialist Journal of the Social Work Today, em 1976, cujo objetivo era ser "uma voz consistente de esquerda no Serviço Social e ajudar a unir radicais do campo" (WAGNER, 1991, p. 82), atingindo, segundo este, milhares de pessoas. Wagner (1991) indica que, nesse período, realizavam encontros entre radicais que aglutinavam até 300 pessoas, em Nova York. Além disso, grupos menores se reuniam em Wisconsin, Boston, New Haven, Connecticut, Chicago e Philadelphia.

Wagner (1991) caracteriza os assistentes sociais radicais dos anos 1960 como aqueles que faziam a autocrítica ao se considerarem "privilegiados" e "opressores dos pobres", dos negros e de grupos do "Terceiro Mundo". Estavam interessados em utilizar suas posições dentro dos serviços sociais para promover causas políticas mais amplas, com permeabilidade ao pensamento marxista e socialista, contribuindo para que se percebessem como classe trabalhadora. O Serviço Social se apresentava como uma profissão identificada com o "cliente ${ }^{6 "}$ e também como uma organização política.

Fergunson (2011, 2016), Healy (2000) e Mullaly (1998) ratificam a existência da tradição "radical" nos EUA. Indicam alguns elementos que influenciaram no SSR, na década de 1970: Sociologia, que crescia, nesse período, como disciplina acadêmica; o Movimento Settlement (movimento de assentamento comunitário dos prestadores de ajuda); a emergência do Serviço Social radical no Reino Unido, Canadá e Austrália; o Movimento de Reconceituação Latino-Americano (MRLA); os movimentos de resistência à época, tais como contra a guerra do Vietnã, o movimento dos direitos civis dos negros e a frente de liberação dos homossexuais. Segundo Ferguson (2011), esses movimentos foram influenciados pelo movimento mundial estudantil, primordial na "Primavera de Praga", em 1968, e no reinício do movimento dos trabalhadores franceses, desembocando na maior greve geral da história (Paris, 1968). O SSR também foi influenciado por ativistas socialistas e feministas anteriores à década de 1970, quando esses movimentos tinham uma preocupação para além do alívio imediato das privações sociais, visando, também, a mudanças estruturais e econômicas.

Galper (1980) argumenta que o interesse em associar ideias radicais com a teoria e a prática do Serviço Social cresce no contexto das dificul-

${ }^{6}$ Utilizaremos o termo cliente, entre aspas, significando que foi usado pelo autor de referência. 


\section{hevistg a p paעtg}

\} OS MOVIMENTOS CONTESTATÓRIOS NO SERVIÇO SOCIAL - EIRAS, A. A. L. T. S.; YAZBEK, M. C.; SANTOS, C. M. \} DOI: $10.12957 /$ REP.2017.32744

dades geradas nos países capitalistas ocidentais e seus rebatimentos nos profissionais e nos "clientes" da assistência pública, acentuando a descrença nas reformas no capitalismo. Healy (2000) também indica a existência de "Teorias Práticas Críticas", que emergiram em uma conjuntura de massiva agitação social e econômica que acompanha o abandono em grande escala do Estado de Bem-Estar Social. Isso significa o desaparecimento das certezas sobre a oferta básica de serviços sociais, agravada pela linguagem do "gerencialismo" sobre o "bem-estar" introduzidos na década de 1970.

De acordo com Maycon Payne (1995, p. 258), o SSR surge como crítica ao trabalho social "tradicional (psicodinâmica)" e a outras teorias que se sustentam em explicações psicológicas dos problemas sociais, bem como crítica às teorias funcionalistas e ao sistema de serviço de assistência à classe trabalhadora naquele período histórico. Mullaly (1998), por sua vez, afirma que o SSR critica o Serviço Social tradicional pelo fato de este patologizar a opressão da população, oferecendo explicações individualistas para os problemas sociais.

Para Mullaly (1998), os assistentes sociais radicais reconhecem a conexão entre preocupações privadas e debates públicos. Há aqueles que consideram a conscientização pessoal como precedente à mudança política e se esforçam para a conscientização das pessoas acerca de suas formas de desigualdade, limites, opressão etc. Para esses, Paulo Freire é um teórico relevante.

Já os que concebem a realidade social objetivamente esforçamse pela mudança das condições materiais e dos modelos estruturais dentro das linhas socialistas. Para eles, o conhecimento e a realidade social são externos ao indivíduo. A realidade social é composta por estruturas concretas e tem um impacto determinista no desenvolvimento individual. Organizam, mobilizam os "clientes" dos serviços, sindicatos e outros grupos ativistas para a transformação social.

Para o autor, essas duas abordagens apresentam uma falsa dicotomia. De acordo com ele, na perspectiva dialética, os indivíduos não são só objeto da ordem social, mas também sujeitos capazes de se mover além dela. Assim, o Trabalho Social estrutural incorporaria ambas as teses da tradição radical na sua base teórica.

Payne (1995) assinala as formas de atuação do SSR, através da ação coletiva " devendo o profissional se unir às instituições da classe trabalhadora, sobretudo aos sindicatos, bem como participar de ações políticas e atividades comunitárias, descentralizando e democratizando o trabalho de equipe. O trabalho individual com "clientes" é muito importante na direção de fazer com que eles compreendam as opressões da classe dominante, distinguindo as necessidades materiais das necessidades pessoais, evitando a individualização e a culpabilização dos "clientes" por seus problemas sociais. Destaca a perspectiva radical baseada nos trabalhos do brasileiro Paulo Freire, considerando essa vertente "particularmente 


\section{ReVistg QIII PaUtg}

\} OS MOVIMENTOS CONTESTATÓRIOS NO SERVIÇO SOCIAL - EIRAS, A. A. L. T. S.; YAZBEK, M. C.; SANTOS, C. M. DOI: 10.12957/REP.2017.32744

importante". Afirma que essa concepção defende que a luta pela sobrevivência somente se consegue mediante uma mudança revolucionária. Ele afirma que essa "filosofia conduziu a uma 'reconceptualização' do trabalho social da América Latina" (PAYNE, 1995, p. 262).

Galper (1980, p. 28) concebe o SSR como "aquele que contribui para a construção de um movimento de transformação para o socialismo pelo seu próprio esforço e utilizando-se de sua prestação de serviços. [...] É um Serviço Social socialista". Considera que o "conceito-chave do modo socialista de análise inclui a análise materialista e dialética que se encontra na metodologia marxista" (GALPER, 1980, p. 29). Ele chama atenção para o fato de que os assistentes sociais radicais são "radicais e assistentes sociais" ao mesmo tempo, ou seja, possuem compromisso político socialista e sua categoria profissional é a de assistente social. Ele critica a postura reformista e chama atenção para não se confundir estas com o SSR, afirmando que "devemos trabalhar a pequenos passos [...]. Devemos, porém, agir de modo a impedir o beco sem saída do reformismo, e construir rumo a uma transformação fundamental" (GALPER, 1995, p. 32).

Em relação ao Canadá - até o presente momento -, identificamos que a crítica ao Serviço Social tradicional se restringiu à Província de Quebec, isto é, ao Canadá francês. Hill e Serwatowski (1972) afirmam que essa região é uma espécie de "Latino-América desarrollada". Eles declaram que, assim como os profissionais da América Latina questionaram os valores recebidos dos EUA, isto também aconteceu no Quebec. Para eles, os profissionais trabalhadores sociais (TSP) nesta província possuem um bom status, sendo reconhecidos e aceitos pela comunidade, "clientela" e outros profissionais, quando em equipes interdisciplinares. Além disso, possuem boa formação profissional, com bons salários, e exercem cargo de direção em todos os departamentos de Serviço Social, escolas e agências privadas.

Rondeau e Commelin (2007) afirmam que foi nos anos de 1950 que o Serviço Social, no Canadá, se emancipa da influência religiosa, tendendo à ruptura com o confessionalismo e com a caridade organizada, passando a se ver como profissão e não como vocação. É daí que surgem as premissas para o Serviço Social quebequense francófono. Mais tarde, em 1960 - no princípio da "Revolução Tranquila" - há um desenvolvimento nos serviços sociais.

Para Hill e Serwatowski (1972), os acontecimentos de outubro de 1970 marcam uma nova etapa na história de Quebec e os assistentes sociais são influenciados por essas mudanças, o que se reflete no Serviço Social. Destacam-se duas concepções: aqueles profissionais influenciados pela psiquiatria, colocando-se como agentes do sistema, seguindo a adaptação do indivíduo ao sistema; já o outro grupo, crescente neste período, deseja as mudanças sociais, e afirma: "Si queremos comprometernos a fondo com los câmbios sociales de nuestro tiempo, si queremos ser agentes activos del cambio, no podemos evitar tomar posición como coletictividad profesioanl 


\section{hevigta all pattg}

\} OS MOVIMENTOS CONTESTATÓRIOS NO SERVIÇO SOCIAL - EIRAS, A. A. L. T. S.; YAZBEK, M. C.; SANTOS, C. M. \} DOI: $10.12957 /$ REP.2017.32744

frente a los problemas sociales y econômicos de La hora" (MELVYN apud HILL; SERWATOWSKI, 1972, p. 55).

É necessário destacar a grande influência do assistente social brasileiro, um dos protagonistas do MRLA, Vicente de Paula Faleiros, no Serviço Social em Quebec neste marco histórico.

\subsection{Portugal e Espanha ${ }^{7}$}

Os países da Península Ibérica possuem um passado glorioso em relação às "grandes navegações" e ao contato com o Continente Americano. Portugal, até meados da década de 1970, manteve colônias em países da África. Mas, no século XX, a inserção desses países na conjuntura econômica europeia ocorre de modo subordinado, em relação aos países capitalistas desenvolvidos. Conforme Hobsbawm (1996, p. 237), a Comunidade Europeia, formada em 1957 (como uma resposta "antissoviética" e como "contraponto" aos EUA), envolvia França, República Federal da Alemanha, Itália, Países Baixos, Bélgica e Luxemburgo. Apenas em 1986 Portugal e Espanha passam a se inserir nesse grupo.

Em Portugal, na passagem dos anos 1960 para 1970 ao derrube da ditadura, em 1974, há um processo de questionamento da neutralidade da profissão, do exercício profissional em projetos de desenvolvimento comunitário, associados ao desenvolvimentismo e à questão colonial, num contexto de resistência à ditadura e ao Serviço Social tradicional (MARTINS, 2002; 2010). Contribuem para tal o processo de politização e o envolvimento de assistentes sociais no movimento pela liberdade sindical, distanciandose da legitimidade atribuída pela Ditadura Salazarista e fazendo a aproximação às correntes do pensamento crítico pelo diálogo entre o cristianismo e o marxismo, a pedagogia de Paulo Freire, a Revista Debates Sociais (CBCISS) e as produções que chegam do MRLA (SANTOS apud EIRAS; SANTOS, 2017).

Com a Revolução de 25 de Abril de 1974, tendências do MRLA, provenientes sobretudo da Argentina, Chile e Brasil, fazem-se sentir na formação. Profissionais e estudantes não aceitam ser chamados de assistentes sociais, associados à assistência e à ditadura, identificando-se como trabalhadores sociais, na condição de assalariados no mercado de trabalho (SANTOS e MARTINS, 2016).

Reis e Maurício (2005, p. 257) encontram um "certo paralelismo" entre as mudanças postas pela Revolução de Abril e a "conjuntura revolucionária" política da América Latina. No que se refere à formação, ressaltam o impacto da Reconceituação nas escolas através do uso corrente de biblio-

\footnotetext{
${ }^{7}$ Neste mesmo volume, há um artigo intitulado Trabajo Social en la realidad española en los años 60-80: a la búsqueda de autodefinición y reconocimiento professional, que se dedica à análise deste período na Espanha.
} 


\section{ReVistg QIII PaUtg}

\} OS MOVIMENTOS CONTESTATÓRIOS NO SERVIÇO SOCIAL - EIRAS, A. A. L. T. S.; YAZBEK, M. C.; SANTOS, C. M. DOI: $10.12957 /$ REP.2017.32744

grafias de autores latino-americanos vinculados ao MRLA, bem como na utilização de teóricos como Marx e Engels. Assiste-se a um aprofundamento da teorização do Serviço Social e a uma maior articulação entre teoria e prática.

Quanto às organizações profissionais, as autoras destacam a ação desenvolvida pelo sindicato de profissionais de Serviço Social (criado em 1950) e pela Associação de Profissionais de Serviço Social (APSS "1977). Para elas, essas instituições contribuíram muito com a divulgação do MRLA no Serviço Social em Portugal. Destacam-se a realização de cursos e eventos que tiveram como participantes alguns protagonistas do MRLA, como Herman Kruse, José Paulo Netto e Natalio Kisnerman. Houve acesso a editoras estrangeiras, possibilitando conhecer obras publicadas na América Latina, sendo criada a publicação Cadernos, com influência de Herman Kruse, Juan Martínez, Ander Egg, José Paulo Netto e Vicente de Paula Faleiros.

Martins (2002, p. 10) indica os traços principais do chamado Serviço Social crítico: o processo de politização dos assistentes sociais por diferentes vias, refletindo na ação profissional; existência de práticas de resistência isolada, como alternativas ao Serviço Social tradicional e à ditadura; recusa da neutralidade da profissão; comprometimento com os interesses das populações com quem trabalhavam; estratégias de práticas de consciencialização social e de emancipação; orientação para a mudança social e para a transformação dos processos e das estruturas que perpetuam a dominação e a exploração. Entretanto, essa tendência crítica foi restrita a um pequeno grupo de assistentes sociais portuguesas.

A bibliografia espanhola também indica a presença da crítica ao Serviço Social tradicional, no contexto de efervescência política e cultural, face à ditadura franquista. Sarasa (apud FEU, 2005, p. 178) indica que, ao final da ditadura, existiam dois modelos de Serviço Social: um oficial e um oficioso. O "oficial" possuía cariz humanista, individualista e assistencialista; o "oficioso" priorizava critérios de justiça social e era ligado ao ativismo político. O primeiro centrava seu trabalho nas próprias instituições, com atribuições reacionárias, e o segundo, no trabalho em comunidades dos bairros, assumindo-se como "agente de mudança".

Montserrat Feu (2005) afirma que o MRLA teve forte influência na Espanha, à qual se somou: a presença do italiano Marco Marchioni para dirigir um projeto de desenvolvimento comunitário de âmbito nacional; a obra de Paulo Freire; a teologia da libertação, de origem latino-americana; e o movimento europeu da "antipsiquiatria". A autora indica três aspectos de influência do MRLA: o assistente social como "agente de mudança"; o termo "conscientizar" a população; a necessidade de repensar a metodologia e a técnica do trabalho social (FEU, 2005, p. 183). Para ela, tais concepções se fundamentavam nas correntes sociológicas críticas e na finalidade de alcançar uma sociedade mais justa, sustentada em conteúdos ideológicos das teorias marxistas e revolucionárias do período. 


\section{Considerações finais}

Podemos afirmar, pelo exposto, que os movimentos contestatórios aos quais se vincula o Serviço Social nos diferentes países são expressões das mudanças societárias e conjunturais, solo das manifestações e lutas sociais desse período. Verifica-se o envolvimento de grupos de assistentes sociais com os movimentos dos trabalhadores (sindicatos e partidos) e com os movimentos de enfrentamento com o Estado, na luta pelos direitos civis, políticos, econômicos e sociais, na perspectiva de continuidade dos avanços ou mesmo de superação da sociedade capitalista. Além disso, também na defesa ou na resistência ao desmantelamento do Estado de Bem-Estar Social. Observa-se a organização dos assistentes sociais em associações ou sindicatos, também presente nesses processos.

Nos países analisados, há expressões críticas ao Serviço Social tradicional. Há também vínculo entre as expressões críticas e os movimentos contestatórios. Ou seja, as expressões críticas são potencializadas e mesmo enraizadas nos movimentos do período, o que se explicita diretamente na defesa dos interesses da população ou dos "clientes" atendidos pelos serviços sociais, bem como na compreensão de que essa defesa inclui a necessidade de alterações estruturais, de mudanças sociais, que supõem a ação na realidade social como requisito da ação profissional crítica. Interessa aos profissionais atuar no processo de consciência social, junto aos "clientes" e à população ou ao público-alvo dos serviços.

Tal conteúdo é convergente com o posicionamento dos assistentes sociais no MRLA. Ainda que não seja possível afirmar a interlocução entre tais posições e o MRLA em todos os países, nos EUA houve referência direta ao movimento e à sua produção; em Portugal e Espanha, com certeza houve interlocução bibliográfica e intercâmbio entre protagonistas desse movimento. Já no Canadá, ainda precisamos avançar na análise da bibliografia, mas podemos atestar, pelas entrevistas realizadas, que houve interlocução entre profissionais que contribuíram com a construção de referências críticas em Quebec.

No Serviço Social, os movimentos sociais, culturais, políticos e econômicos se expressam em críticas a um Serviço Social tradicional e/ou ao sistema capitalista como um todo. Essa postura crítica traduz-se no denominado Serviço Social crítico e no denominado Serviço Social radical, variando de acordo com o país.

No Serviço Social crítico e/ou radical, há recorrência ao marxismo. Mas, como apresentamos, existem compreensões diferentes e não houve, em qualquer um dos países, a configuração de uma hegemonia profissional referenciada na perspectiva marxista.

Observamos alguma semelhança entre o MRLA e o Serviço Social crítico e/ou radical nos quatro países. Essa constatação nos faz refletir acerca dos diferentes processos sociais e de conteúdos neles presentes, que nos 


\section{ReVistg QIII PaUtg}

\} OS MOVIMENTOS CONTESTATÓRIOS NO SERVIÇO SOCIAL - EIRAS, A. A. L. T. S.; YAZBEK, M. C.; SANTOS, C. M. \}

DOI: $10.12957 /$ REP.2017.32744

aproximam, com possibilidade de convergências. Por essa razão, talvez possamos, na atualidade, reencontrar os caminhos trilhados, fortalecendonos mutuamente na construção de estratégias progressistas e emancipatórias, nas circunstâncias que se colocam neste momento e que nos desafiam em nível mundial.

Por outro lado, o Serviço Social brasileiro, ao consolidar a ruptura com suas bases tradicionais no decorrer da década de 1980, constitui uma singularidade, havendo o avanço da perspectiva crítica e a construção hegemônica de um projeto profissional crítico de âmbito nacional. Posição talvez que nos confira alguma responsabilidade em contribuir com os assistentes sociais que se propõem à construção de referências críticas na profissão nos diferentes países. 
\} OS MOVIMENTOS CONTESTATÓRIOS NO SERVIÇO SOCIAL - EIRAS, A. A. L. T. S.; YAZBEK, M. C.; SANTOS, C. M. \} DOI: $10.12957 /$ REP.2017.32744

\section{Referências}

ALAYÓN, N. Trabajo social latinoamericano - a 40 años de la Reconceptualización. Buenos Aires: Espacio Editorial, 2005.

EIRAS, A. A. L. T. S. Grupos e Serviço Social: explorações teórico-operativas. Tese (Doutorado) - Escola de Serviço Social, UFRJ, Rio de Janeiro, 2006.

EIRAS, A. A. L. T. S.; SANTOS, C. M. Movimento de Reconceituação do Serviço Social na América Latina e interlocuções internacionais: os movimentos contestatórios no Serviço Social europeu e norte-americano no período de 1960 a 1980. In: XIII CONGRESO ESTATAL E I IBEROAMERICANO DE TRABAJO SOCIAL. Mérida/Espanha, out. 2017.

FALEIROS, V. P. Reconceptualización del trabajo social en Brasil: una cuestión en movimiento? In: ALAYÓN, N. Trabajo social latinoamericano-a 40 años de la Reconceptualización. Buenos Aires: Espacio Editorial, 2005.

FEU, M. La construcción del trabajo social en España. Influencias de la Reconceptualización. In: ALAYÓN, N. Trabajo social latinoamericano - a 40 años de la Reconceptualización. Buenos Aires: Espacio Editorial, 2005. FERGUNSON, I. Um outro Serviço Social é possível! - reivindicando a tradição radical. Revista Em Pauta, v. 9, n. 27, jul. 2011.

- A esperança acima do medo: o ensino do Serviço Social rumo a 2025. In: MARTINS, A. et al. Serviço Social Portugal-Brasil. Formação e exercício em tempos de crise. Campinas: Papel Social, 2016.

GALPER, G. Política social e trabalho social. São Paulo: Cortez Editora, 1980.

HILL, R; SERWATOWSKI, W. Servicio Social en una América Latina desarrollada? Aspectos profesionales en el Canadá francés. Revista Seleciones de Servicio Social, n. 16, 1972.

HOBSBAWM, E. A era dos extremos. O breve século XX. São Paulo: Companhia das Letras, 1996.

IAMAMOTO, M. V. et al. Projeto de pesquisa. O Movimento de Reconceituação do Serviço Social na América Latina (Argentina, Brasil, Chile e Colômbia): determinantes históricos, interlocuções internacionais e memória, 2016.

HEALY, K. Trabalho social: perspectivas contemporâneas. Galiza: Morata/ Fundación Paidéia, 2000.

MARTINS, A. Serviço Social crítico em tempos de ditadura em Portugal. In: I CONGRESSO NACIONAL DE SERVIÇO SOCIAL, Aveiro/Portugal, 23 e 24 de maio, 2002.

. Génese, emergência e institucionalização do Serviço Social português. Lisboa: Porgress, 2010. 
MARTINS, A.; SANTOS, C. M. Tendências "críticas" na formação do assistente social em Portugal. In: Serviço Social Portugal-Brasil. Formação e exercício em tempos de crise. Campinas: Papel Social, 2016.

MOLJO, C. B. Trabajadores sociales en la historia. Una perspectiva transformadora. Buenos Aires: Espacio Editorial, 2005.

MULLALY, R. Structural Social Work. Toronto, Ontario: McClelland, 1998. REIS, M. H.; MAURÍCIO, C. S. Aportaciones para uma reflexión em torno al Movimiento de Reconceptualziación del Servicio Social em el marco português. In: ALAYÓN, N. Trabajo social latinoamericano - a 40 años de la Reconceptualización. Buenos Aires: Espacio Editorial, 2005.

RONDEAU, G.; COMMELIN, D. La profissión de trabajador social em Quebec. In: DESLAURIERS, J. P.; HURTUBISE, Y. El trabajo social internacional. Elementos de comparación. Buenos Aires, Lumen Grupo Editorial, 2007.

NETTO, J. P. Portugal do fascismo à revolução. Porto Alegre: Mercado Aberto, 1986.

- Ditadura e Serviço Social. São Paulo: Cortez, 1991.

PAYNE, M. Teorías contemporáneas del trabajo social. Una introducción crítica. Barcelona, Buenos Aires, México: Ediciones Paidos, 1995.

WAGNER, D. Movimentos radicais nos serviços sociais: uma base teórica. In: Revista Serviço Social e Sociedade, São Paulo, n. 35, 1991.

DOI: $10.12957 /$ rep.2017.32744

Recebido em 15 de setembro de 2017.

Aprovado para publicação em 13 de outubro de 2017.

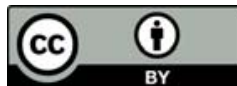

A Revista Em Pauta: Teoria Social e Realidade Contemporânea está licenciada com uma Licença Creative Commons Atribuição 4.0 Internacional. 